\title{
Effect of the Grain Structure of the Substrate on Magnetic Properties of Electrodeposited Fe-Ni Films* ${ }^{*}$
}

\author{
(Received April 18, 1963)
}

Recently a great deal has been learned about the preparation of magnetic thin films by electro-deposition (1) (8), but relatively few literature have been available on the effect of various substrates and their surface condition on magnetic properties of the film produced $(6)(8)(9)$. The authors examined the magnetic properties of $80 \% \mathrm{Ni}-\mathrm{Fe}$ alloy films electrodeposited on various substrates under the following conditions: the anode, Fe-Ni alloys $0.3 \mathrm{~mm}$ thick, $0.6 \mathrm{~mm}$ wide, and $80 \mathrm{~mm}$ long, substrate; copper and phosphor bronze containing $5.5 \%$ tin; surfaces: (1) pickled and degreased, (2) emery-polished $(0 \sim 05)$ and pickled, (3) pickled, degreased, and polished electrolytically : electrolyte : $\mathrm{FeSO}_{4} \cdot 7 \mathrm{H}_{2} \mathrm{O} 24 \mathrm{~g} / \mathrm{L}, \mathrm{NiSO}_{4} \cdot 7 \mathrm{H}_{2} \mathrm{O} 120 \mathrm{~g} / \mathrm{L}, \mathrm{H}_{3} \mathrm{BO}_{3} 15$ $\mathrm{g} / \mathrm{L}, \mathrm{NaCl} 15 \mathrm{~g} / \mathrm{L}$ and saccharin $5 \mathrm{~g} / \mathrm{L}$, held at $\mathrm{pH} 2.7$; and at $35^{\circ} \mathrm{C}$ current density : $3 \mathrm{~A} / \mathrm{dm}^{2}$; current efficiency; $100 \%$; deposited film thickness; $1.5 \mu$.

Hysteresis curve were measured with a $80 \% \mathrm{Ni}$ film deposited on an annealed copper plate surface-treated according to the above-mentioned procedure (3). Photo. 1 (a) refers to the curve as measured in a magnetic field applied perpendicularly to the direction of rolling, and Photo. $l(b)$ is the one measured in the parallel field. The latter shows clearly the uniaxial

* This work was supported by the Central Research Laboratory, T. D. K. Electronics Co., Ltd., Tokyo.

$\dagger$ Presented at the fourty-nineth meeting of the Japan Institute of Metals, held at Akita in October, 1961. This paper have been already published in Japanese in the Journal of the Japan Institute of Metals, 26 (1961), 396.

(1) L. Leimer: Z. Naturfor., 10 a (1955), 1030.

(2) L. Leimer: Z. Naturfor., 11 a (1656), 649.

(3) L. Leimer: Z. Metallk., 47 (1956), 631.

(4) L. Leimer: Z. Naturfor., 12 a (1957), 550.

(5) L. Leimer: Z. Physik., 150 (1958), 99.

(6) J. C. Lloyd and R. S. Smith: J. Applied Physics, Suppl., 30 No. 4 (1961), $274 \mathrm{~S}$.

( 7 ) T. Tsu : Plating, 47 (1961), 632.

(8) S. Morioka, et al: J. Japan Inst. of Metals, 25 (1961), 679.

(9) Y. Sasaki, et al: Presented at the Joint Convention of the Institute of 4 Electrical Engineering of Japan, Osaka, April, (1961), [Materials for Electrical Use No. 461]. anisotropy. But, with the same material surface-treated according to the procedure ( 1 ), the square type hysreresis curve was measured in the parallel magnetic field and the direction perpendicular to the roll direction was found to be the direction of hard magnetization.

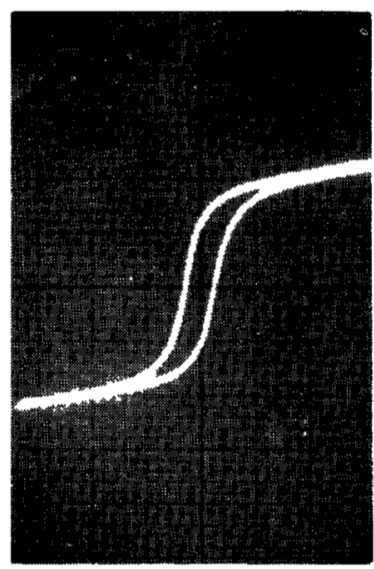

(a)

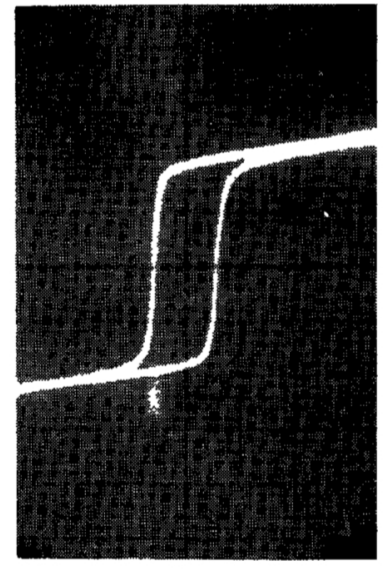

(b)
Photo. $12 \mathrm{KC} / \mathrm{S}$ hysteresis loops of a $80 \% \mathrm{Ni}-\mathrm{Fe}$ film electrodeposited on a rolled copper plate, as measured in a magnetic field applied perpendicularly (a) and in parallel (b) to the rolling direction of the substrate.

Thus, the situation is reverse to the phenomenon observed in the case of electropolished substrate. It is to be noted, however, that in the substrate surfacetreated according to the procedure (1), there are two cases where the uniaxial anisotropy appears and does not appear, depending on the surface condition of the substrate. It seems that the reason for this depends on streaks caused by the rolling process. On the other hand, the surface-treatment (2) of the substrate rendered magnetic properties to agree completely with the results obtained by Lloyd et $\mathrm{al}^{(6)}$, the direction of easy magnetization being parallel to that of emery polishing.

The examination with a microinterferometer of the 
electropolished surfaces of substrates prior to deposition has revealed that the surface have a quite smooth mirror luster and the roughness less than $0.5 \mu$, and that their grains are elongated in the direction of rolling (Photo. 2). Then, such substrates were annealed clearly the secondary recrystallization. The magnetic properties of thin films electrodeposited on these substrates seldom showed an uniaxial anisotropy as. shown in Photo. 4. Then, it might be thought that the uniaxial anisotropy caused by the deposition on an

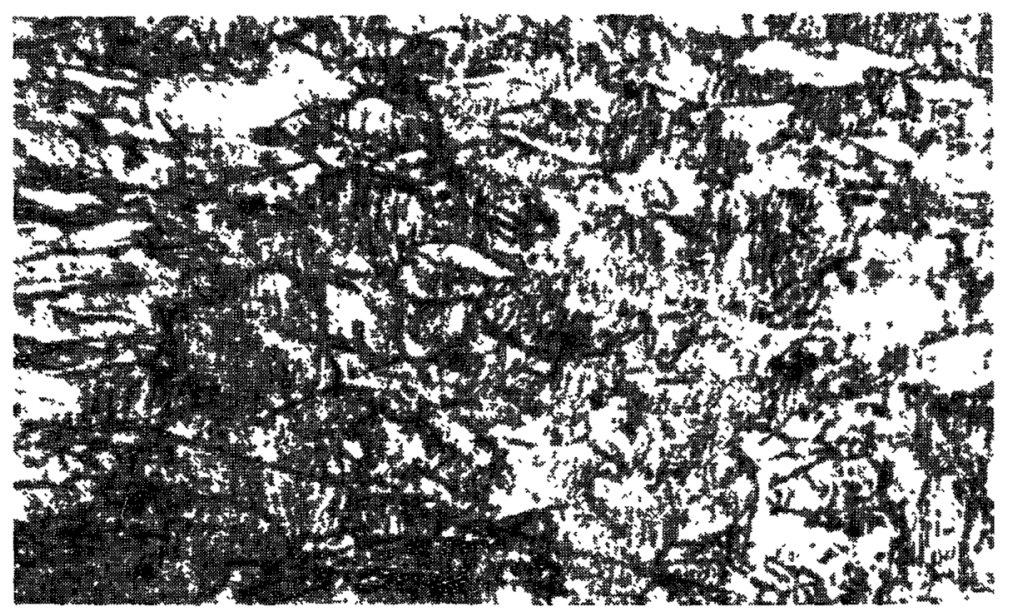

Pohto. 2 Microstructure of a rolled copper plate. $\left(\mathrm{FeCl}_{3}+\mathrm{HCl}\right.$ alcoholic soln. etch $)(\times 250)$

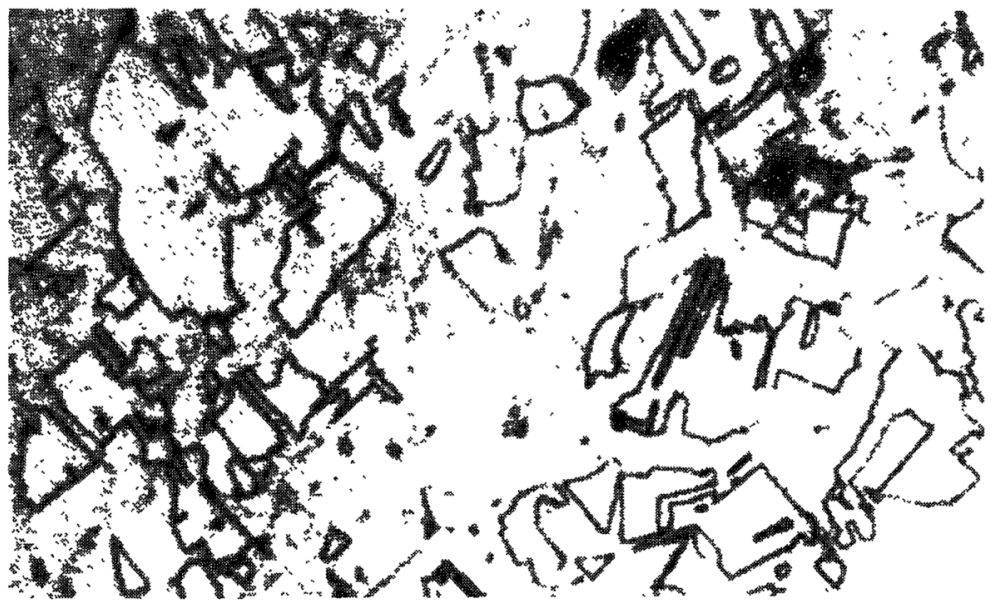

Photo. 3 Microstructure of an annealed copper plate. ( $\mathrm{FeCl}_{3}+\mathrm{HCl}$ alcoholic soln. etch $)(\times 250)$

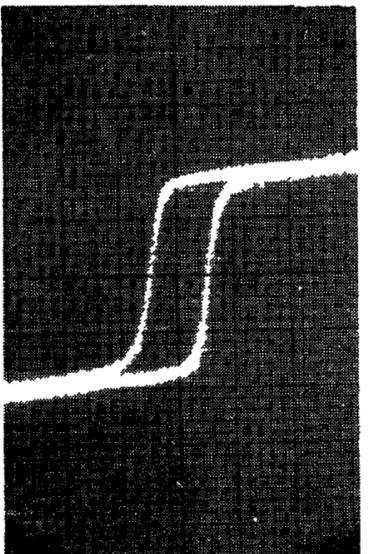

(a)

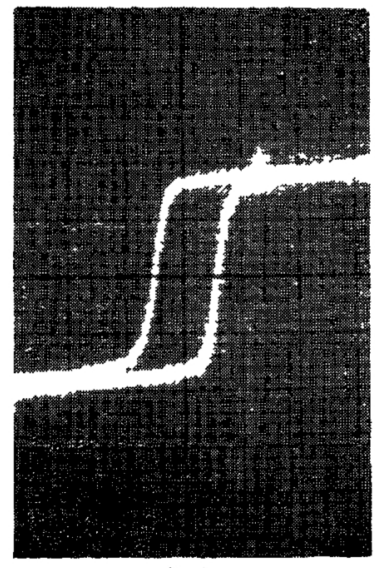

(b)
Photo. $42 \mathrm{KC} / \mathrm{S}$ hysteresis loops of a $80 \% \mathrm{Ni}$-Fe film electrodeposited on an annealed copper plate, as measured in a magnetic field applied perpendicularlly (a) and in parallel (b) to the rolling direction of the substrate.

at $400^{\circ} \mathrm{C}$ for $1 \mathrm{hr}$ in nitrogen atmosphere and electropolished. Their grain structures (Photo. 3) indicate electropolished surface of the substrate may be infiuenced by crystal grains of the substrate. But, the examination of commercial copper plates having crystalline structures similar to that shown in Photo. 3 and surface-treated according to (3) revealed no uniaxiality.

From the above mentioned results, it may be evident that the uniaxial anisotropy appearing by deposition on electropolished surfaces is connected to the crystalline structure of the substrates. The $\mathrm{Fe}-\mathrm{Ni}$ alloy film precipitated by electrodeposition on an electropolished surface with the crystalline structure such as shown in Photo. 2, has, for some reasun the direction of easy magnetization perpendicular to the direction of rollng and that with the crystal structure such as shown in Photo. 3 has isotropic directions of the easy magnetization. The details are now under investigation.

By Tsutomu limura*, Sadahiko Sekiguchi** and Mutsuo Sasaki**

* Now at the Central Research Laboratory, Hitachi Ltd., Tokyo.

** Now at the Central Research Laboratory, T. D. K. Electronics Co., Ltd., Tokyo. 